Beskydy, 2016, 9 (1-2): 31-40

(C) Mendelova univerzita v Brně

ISSN: 1805-9538 (Online)

http://dx.doi.org/10.11118/beskyd201609010031

\title{
Photosynthetic response of mountain grassland species to drought stress is affected by UV-induced accumulation of epidermal flavonols
}

\author{
Barbora Rapantová, Karel Klem, Petr Holub, Kateřina Novotná, Otmar Urban
}

Global Change Research Institute CAS, Bèlidla 4a, Brno CZ-603 00, Czech Republic

\begin{abstract}
Rapantová B., Klem K., Holub P., Novotná K., Urban O. 2016: Photosynthetic response of mountain grassland species to drought stress is affected by UV-induced accumulation of epidermal flavonols. - Beskydy, 9 (1-2): 31-40
\end{abstract}

Interactive effects of drought and ultraviolet (UV) radiation on $\mathrm{CO}_{2}$ assimilation rate and accumulation of epidermal flavonols were studied in two herbs (Hypericum maculatum and Rumex obtusifolius) and two grasses (Agrostis capillaris and Holcus mollis) under field conditions of Beskydy Mts. The main objective of this study was to evaluate a protective role of epidermal flavonols against drought stress. Experimental shelters were used to manipulate amount of incident precipitation and UV radiation intensity for 12 weeks (May-July). The light-saturated $\mathrm{CO}_{2}$ assimilation rate $\left(A_{\max }\right)$ and the content of epidermal flavonols were regularly measured at intervals of 2-3 weeks during the entire period. Drought-induced reduction of $A_{\max }$ was enhanced by high UV intensity in R. obtusifolius, whereas in other species UV radiation reduced a negative effect of drought. Generally, drought increased flavonol content in leaves as compared to non-stressed plants. Similarly, high UV intensities increased the flavonol content in control plants, but not in drought-stressed ones. Regression analysis between the flavonol content and $A_{\max }$ revealed a positive correlation especially for A. capillaris and R. obtusifolius. In both species, a separation of these relationships was observed as the result of water availability. Thus lower $A_{\max }$ were observed at the same flavonol content in drought-stressed plants when compared to control, well-watered counterparts. We conclude that UV-induced accumulation of epidermal flavonols can alleviate negative impacts of summer drought on photosynthesis, particularly in species with slower ontogeny like H. maculatum and A.capillaris.

Keywords: Agrostis capillaris, $\mathrm{CO}_{2}$ assimilation, drought stress, flavonols, grassland, Holcus mollis, Hypericum maculatum, precipitation, Rumex obtusifolius, UV radiation

\section{Introduction}

Increasing frequency of extreme drought events is projected globally by macro-scale water balance models (Tao et al. 2003) and will likely lead to a significant decrease in ecosystem productivity and ecosystem functions. Even under relatively well-watered conditions an uneven distribution of rainfall during the growing season reduces ecosystem productivity on average by $10-15 \%$ (Hlavinka et al. 2009). The effects of extreme weather events on vegetation and ecosystem functioning are likely to be much stronger than the effects of changes in mean values of temperature and precipitation (Easterling et al. 2000). In addition, among the abiotic stressors, drought and increased intensities of ultraviolet (UV) radiation, and also their mutual interactive effects have received much more attention, because of their potential to impair many plant species (Agrawal et al. 2009). 
Plants have developed a number of adaptation and acclimation mechanisms to cope with drought episodes. One of the most important mechanisms of acclimation is an accumulation of compounds that increase antioxidant capacity and play a role in detoxification of reactive oxygen species frequently forming under drought stress. These compounds include either non-enzymatic (as flavonoids, carotenoids, tocopherols) or enzymatic constituents (Basu et al. 2010). Accumulation of antioxidants is mostly controlled by light conditions, particularly UV radiation intensity (Klem et al. 2015). Especially the group of flavonoids, which is preferentially localized in epidermal cells of leaves, play an important role in protection of photosynthetic apparatus against an excessive UV radiation (e.g. Meijkamp et al. 1999). Because such protective mechanisms play an adaptive role in a drought stress regulation (Gitz and Liu-Gitz 2003) as well as an attenuation of UV radiation (Ibañez et al. 2008), interactive effects of UV and drought in plants are assumed (Cechin et al. 2008). However, the interactive responses to drought and UV radiation are still not well understood as the reported interactions range from antagonistic to synergistic (Mittler 2006). For example, a combination of drought and high UV intensities resulted in an alleviation of negative effect of drought on photosynthesis and transpiration in sunflower plants (Cechin et al. 2008). Alexieva et al. (2001) concluded that both stresses act synergistically to induce biosynthesis of antioxidant compounds. In contrast, Ren et al. (2007) found additive effects of drought and UV radiation in poplar species. Although these interactions were species specific, higher tolerance to both drought and enhanced UV was found in species originating from high altitudes. Some findings attribute the primary role for flavonoid induction to UV (Balakumar et al. 1993), whereas other results suggest an interaction with water stress (Nogués et al. 1998). Besides the accumulation of flavonoids, combined effect of drought stress and UV radiation can also exhibit another mechanisms of interactions as for example through accumulation of osmoregulator proline (Shetty et al. 2002), or production of dehydrin proteins (Schmidt et al. 2000), which may both contribute to increased drought tolerance.

Since drought and UV radiation induce similar protective mechanisms, we tested the hypothesis that UV radiation moderates the negative effects of drought on photosynthesis. In particular, attention was paid to the protective role of epidermal flavonols, a class of flavonoids that have the 3-hydroxyflavone backbone. The hypothesis was tested under natural conditions of a mountain grassland ecosystem.

\section{Materials and Methods}

The manipulation experiment evaluating combined effects of drought and UV radiation was conducted in 2011 within the grassland ecosystem (association Molinio-Arrhenatheretea, class Polygono-Trisetion) at the experimental site Bílý Kř́íż, Moravian-Silesian Beskydy Mts. (49³0’ N, $18^{\circ} 32^{\prime} \mathrm{E}, 890 \mathrm{~m}$ a.s.l.). The mean long-term annual temperature and precipitation are $6.8^{\circ} \mathrm{C}$ and $1312 \mathrm{~mm}$, respectively. The geological bedrock is formed by Spodo-dystric cambisol on Flysch Godulian sandstone. The grassland is regularly cut once per growing season.

Six experimental shelters (dimension $3 \times 2 \mathrm{~m}$ ) were used for the manipulation of incident UV radiation intensity and amount of precipitations. Shelters were formed by plastic lamellas enabling a penetration of natural precipitations (control treatment) or their exclusion (drought treatment). The lamellas (thickness of $3 \mathrm{~mm}$ ) were made from two types of acrylic material (Quinn Plastics, Enniskillen, UK). The first type (UVT Solar) transmitted more than $90 \%$ of incident UV-A and UV-B radiation (UV+ treatment), whereas the second one (Quinn XT) filtered UV-B radiation and a large part of UV-A (UVtreatment). Thus 4 treatments were maintained: [UV-; Control], [UV-; Drought], [UV+; Control], and [UV+; Drought]. All treatments were applied for 12 weeks starting at May 5. Volumetric soil water content, estimated regularly by a ThetaProbe ML2x (Delta-T Devices, Cambridge, UK) at a depth of $15 \mathrm{~cm}$, was reduced at the end of experiment to approximately $36 \%$ at drought plots as compared to control ones (Table 1).

Changes in accumulation of UV-screening compounds (flavonols) and $\mathrm{CO}_{2}$ assimilation rate were studied in two grasses (Agrostis capillaris L. and Holcus mollis L.) and two herbs (Hypericum maculatum Crantz and Rumex obtusifolius L.). In situ measurements were done four times during the drought period at intervals of 2-3 weeks (May 24, June 13, July 7, and July 28). All measurements were done on intact, sun exposed leaves between 10:00 AM and 2:00 PM (Central 
Table 1: The means and standard deviations of volumetric soil moisture (\% vol.) in drought stress and control plots at four measurement dates in 2011 ( $n=3)$.

\begin{tabular}{lcccc}
\hline Date & [UV-; Control], & [UV+; Control], & [UV-; Drought] & [UV+; Drought] \\
\hline May 24 & $53.7 \pm 1.3$ & $54.6 \pm 0.9$ & $25.8 \pm 2.5$ & $23.4 \pm 8.7$ \\
June 13 & $50.8 \pm 1.2$ & $52.4 \pm 1.3$ & $24.0 \pm 1.8$ & $20.9 \pm 8.5$ \\
July 7 & $52.2 \pm 1.2$ & $53.7 \pm 1.5$ & $20.7 \pm 0.5$ & $16.8 \pm 8.9$ \\
July 28 & $54.4 \pm 2.0$ & $55.4 \pm 1.8$ & $20.7 \pm 0.4$ & $17.1 \pm 9.2$ \\
\hline
\end{tabular}

European Time) to minimize the effect of diurnal cycle. Light-saturated rates of $\mathrm{CO}_{2}$ assimilation $\left(A_{\max }\right)$ were determined under ambient $\mathrm{CO}_{2}$ concentration $\left(385 \pm 5 \mu \mathrm{mol} \mathrm{mol}{ }^{-1}\right)$ and constant microclimatic conditions (leaf temperature: 25 $\pm 1^{\circ} \mathrm{C}$, relative humidity: $55 \pm 3 \%$ ) using a Li6400XT gas exchange system (Li-Cor, Lincoln, NE, USA). Constant saturating irradiance (1200 $\mu \mathrm{mol} \mathrm{m} \mathrm{m}^{-2} \mathrm{~s}^{-1}$ ) was provided by LED light source Li-6400-02B (Li-Cor, USA). Flavonol content was determined in vivo by the method of epidermal screening of chlorophyll fluorescence using a Dualex 4 Flav (Force-A, Orsay Cedex, F).

Before the analysis of variance (ANOVA), the normality of data for individual parameters was tested using Kolmogorov-Smirnov test. A threeway fixed-effect ANOVA model was used for the general analysis of drought stress, UV radiation and date of measurement effects separately for each species. To compare the means a Fisher's LSD post-hoc $(p \leq 0.05)$ test was used. Pearson's coefficient of determination $\left(R^{2}\right)$ was calculated to evaluate the power of relationships between flavonol content and $A_{\max }$. All statistical tests were done using a Statistica 12 software (StatSoft, Tulsa, OK, USA).

\section{Results and Discussion}

\section{$\mathrm{CO}_{2}$ assimilation rate}

Light-saturated $\mathrm{CO}_{2}$ assimilation rate $\left(A_{\max }\right)$ showed distinct dynamics during drought period for different species (Fig. 1). Whereas gradual decrease of $A_{\max }$ was found in R. obtusifolius and $H$. mollis, a peak type dynamics was found in H. maculatum and A. capillaris. This peak was observed in A. capillaris earlier during the drought period as compared with H. maculatum. This dynamics was, however, similar for both control and drought stress treatments. Different dynamics in $A_{\max }$ is thus probably not related to drought or UV treatment but it is mostly given by plant ontogeny. The later peak of $A_{\max }$ in $A$. capillaris and particularly in H. maculatum means slower development as compared to another two species. Similar pattern of photosynthetic performance with leaf age was found e.g. by Jurik et al. (1979) in Fragaria virginiana, where maximum photosynthetic capacity coincided with the completion of leaf blade expansion and declined quickly thereafter.

Drought stress reduced $A_{\max }$ in most species, but not in H. mollis. The effect of water deficit was more pronounced in the second and third date of measurement after drought stress initiation. However, the differences between droughtstressed and control plants decreased at the end of experimental period. It is attributed to an advanced senescence (reviewed by Munné-Bosch and Alegre 2004). Senescence reduced $A_{\max }$ also in control plants and the effect of drought was thus likely masked and led to a convergence of photosynthetic performance in droughtstressed and well-watered plants. Earlier senescence induced by drought may result in a reallocation of nutrients to younger leaves keeping thus a photosynthetic performance for longer time (Ono et al. 2001). This mechanism can also contribute to decreasing differences between drought stress and control plants.

In addition, the effect of drought stress on $A_{\max }$ is modulated by UV radiation. While in $R$. obtusifolius was higher effect of drought on $A_{\max }$ observed under UV+ than UV- treatment, the negative drought effect was substantially reduced under UV+ treatment in H. maculatum and A. capillaris. These two species also show shifted maximum of $A_{\max }$ to a later period as compared to R. obtusifolius and H. mollis. Acclimation to UV radiation during an early plant development (a period of $A_{\max }$ rise) can probably induce protective mechanisms against drought, whereas such UV effect is relatively minor in fully developed leaves (a period of $A_{\max }$ decline). Also Winkel et al. (2001) documented an important role of ontogeny in response of Pennisetum glaucum 


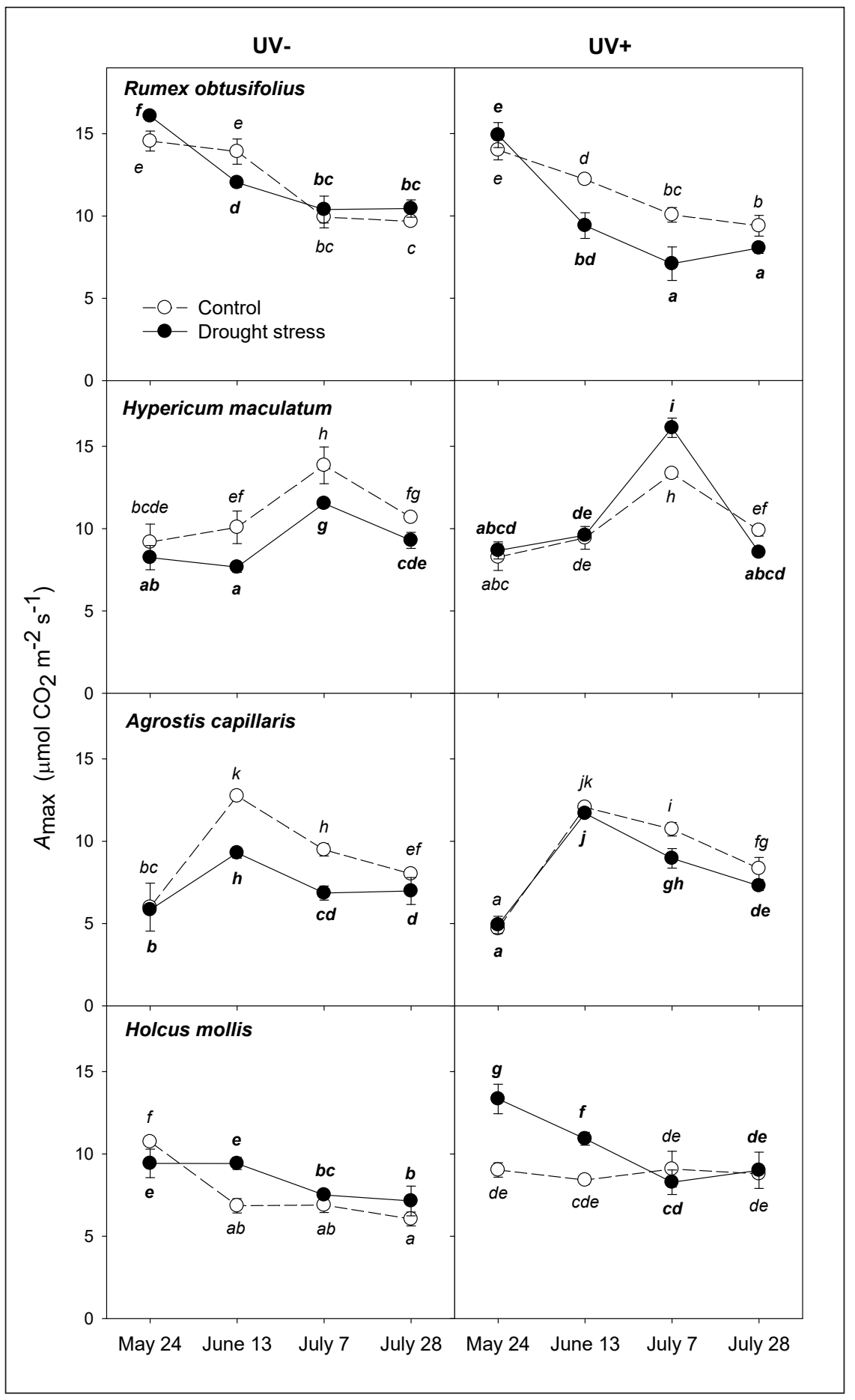

Fig. 1: The effect of drought and UV radiation on light-saturated $\mathrm{CO}_{2}$ assimilation rate $\left(A_{\text {max }}\right)$ in four mountain grassland species. Means (points) and standard deviations (error bars) are presented $(n=3)$. Different letters denote statistically significant differences ( $p \leq 0.05$ ) between treatments (within individual species) using Fisher's LSD post-hoc test. 
(pearl millet) to drought. Under pre-anthesis, stomatal regulation plays a major role in acclimation to drought, but this mechanism becomes negligible after anthesis. They also found that leaf senescence after anthesis is not drought dependent.

Noticeably, drought treatment led to an increase of $A_{\max }$ in H. mollis, particularly at the beginning of the vegetation season. This positive effect persisted under UV- conditions over the whole period investigated. It means that slight water deficit increased $\mathrm{CO}_{2}$ assimilation capacity in rhizomatous $\mathrm{H}$. mollis. Similarly, $\mathrm{Xu}$ and Zhou (2011) found higher resistance of photosynthetic capacity to drought in perennial rhizome grass Leymus chinensis than in perennial bunch Stipa grandis. Also Liancourt et al. (2005) reported high species differences in response to drought treatment in grassland ecosystem. These differences were mainly linked to a competitive ability of species. Species with a high competitive ability respond usually much stronger to water deficit and create thus a space for species with a low competitive ability.

\section{Accumulation of epidermal flavonols}

Epidermal flavonols declined over the vegetation season in R. obtusifolius and H. mollis under ambient precipitation (control; Fig. 2). This decline was more pronounced under UV- than $\mathrm{UV}+$ treatment. Epidermal flavonols remained unchanged or slightly increased during the studied period under drought stress. Such distinct dynamics of epidermal flavonols led to a substantial differences between control and drought-stressed plants at the end of the period studied, particularly under UV- treatment. Similar effect of drought on accumulation of epidermal flavonols was found in H. maculatum and A. capillaris; however, the dynamics of changes were much lower and differences between control and drought-stressed plants were less obvious. Noticeably, A. capillaris had the lowest amount of epidermal flavonols, whereas H. maculatum had the highest one. Tattini et al. (2004) found that drought increased the amount of polyphenols per unit of assimilated $\mathrm{CO}_{2}$, but polyphenols decreased in total, particularly under high radiation intensities. Other studies have found even an increase of total flavonoid amount induced by drought and this accumulation was substantially higher in drought-tolerant than drought-sensitive genotypes (Ma et al. 2014). In agreement with our hypothesis, Nakabayashi et al. (2014) demonstrated that over-accumulation of flavonoids in Arabidopsis thaliana mutants improved drought tolerance and reduced oxidative damage of plants. Accumulation of flavonoids thus appears as one of the most important acclimation mechanisms under drought stress.

\section{Relationships between epidermal flavonols and $\mathrm{CO}_{2}$ assimilation}

To analyse the role of epidermal flavonols in an alleviation of drought stress effect on $A_{\max }$, the relationships between these traits were evaluated separately for each species and water regime (Fig. 3). No significant relationships ( $p>0.05)$ were found in H. maculatum. This species had generally high values of epidermal flavonols even under low UV intensities and sufficient water availability. Such a high constitutive accumulation of flavonols was likely the main reason for no relationships to $A_{\max }$ in $H$. maculatum.

Similar pattern of the relationships between epidermal flavonols and $A_{\max }$ was found in $H$. mollis and R. obtusifolius. Significant relationships were found in control plants, but this was not a case in drought-stressed ones. High variability in $A_{\max }$ under drought stress indicates an involvement of a wide spectrum of other protective mechanisms. These are particularly stomatal and mesophyll resistances reducing water vapour transpiration from leaves or biochemical acclimations such as alterations in photophosphorylation, synthesis/translocation of plant hormones or an accumulation of osmoprotectans (reviewed by Chaves et al. 2003).

On the other hand, significant relationships were found in both control and droughtstressed A. capillaris plants. However, these relationships were substantially distinct. At the same amount of flavonols, $A_{\max }$ was lower under drought stress as compared with control treatment. These differences are probably given by stomatal limitation of $\mathrm{CO}_{2}$ assimilation, whereas the relationship to epidermal flavonols is likely based on biochemical limitation. These data support the hypothesis that flavonoids contribute to an antioxidant capacity of plants against an excessive irradiance (particularly UV) and drought stress (Tattini et al. 2004). For example, Nogués et al. (1998) found that UV radiation delayed and reduced the severity of drought stress through reductions in plant water-loss rates, 


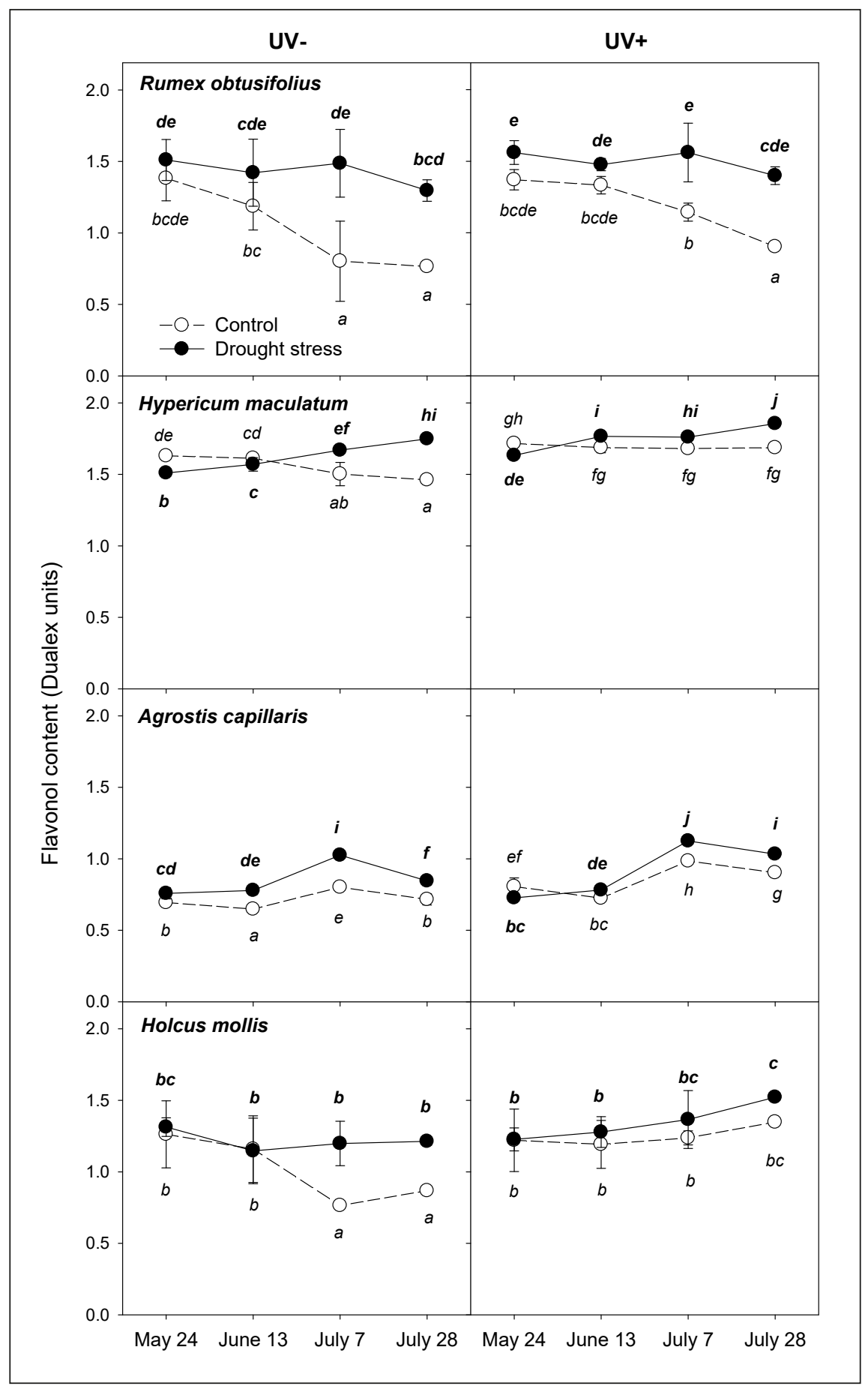

Fig. 2: The effect of drought and UV radiation on epidermal flavonol content in four mountain grassland species. Means (points) and standard deviations (error bars) are presented $(n=3)$. Different letters denote statistically significant differences ( $p \leq 0.05$ ) among all treatments (within individual species) using Fisher's LSD post-hoc test. 


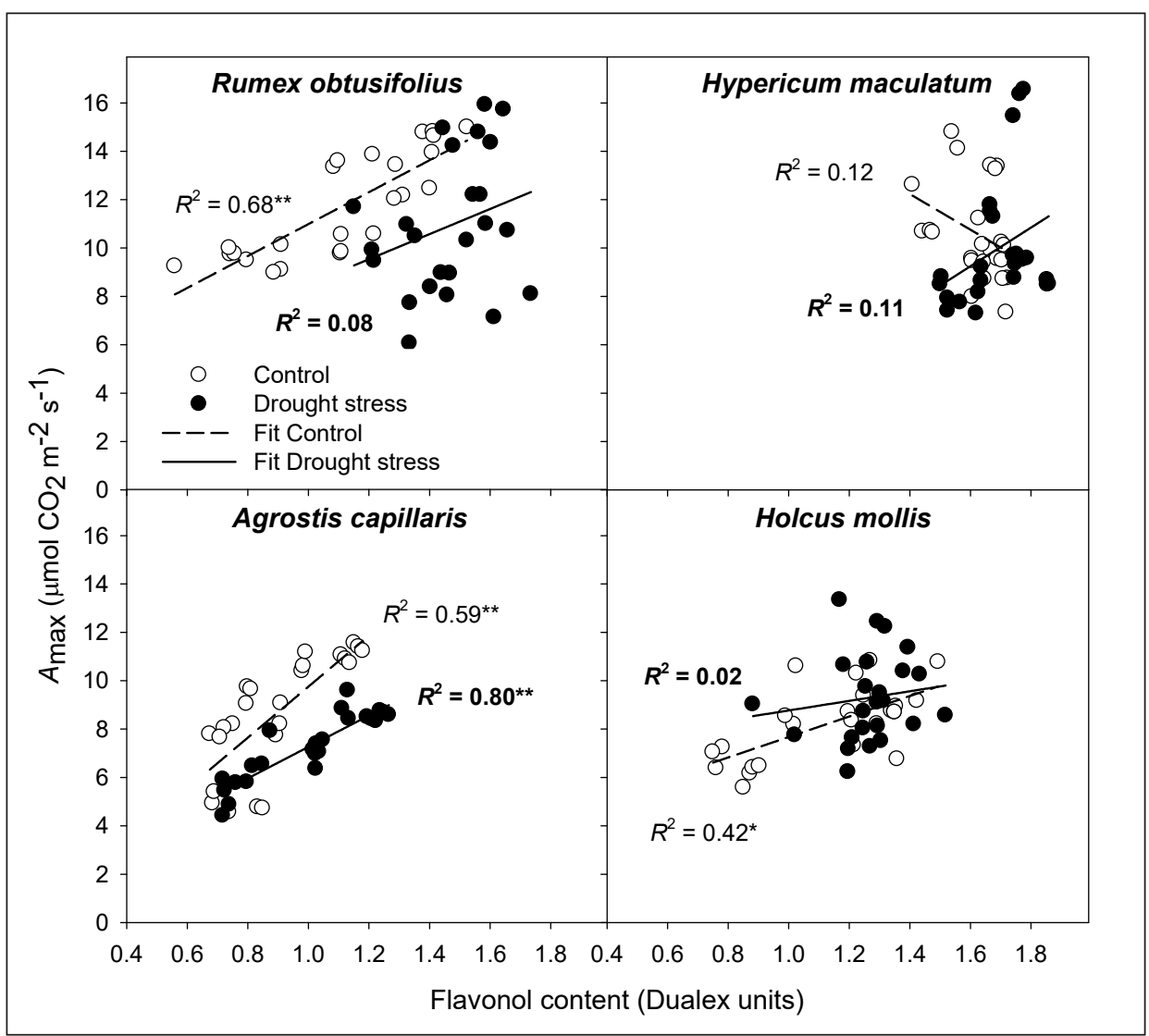

Fig. 3: Relationships between content of epidermal flavonols and light-saturated $\mathrm{CO}_{2}$ assimilation rate $\left(A_{\max }\right)$. The relationships are separated for control and drought stress treatment. Points represent data from individual plots (replications). Pearson correlation coefficients $\left(R^{2}\right)$ are presented $(*$ and $* *$ indicates statistically significant relationship at $p \leq 0.05$ or $p \leq 0.01$, respectively).

stomatal conductance, and leaf area. Alexieva et al. (2001) reported in pea as well as wheat plants that UV and drought stress may induce adaptations reducing plant damages caused by the other factor. Likewise, Gitz et al. (2005) showed that some soybean cultivars respond to enhanced UV intensities by increasing water use efficiency associated with changes in stomatal development and functioning.

\section{Conclusions}

Drought stress reduced $\mathrm{CO}_{2}$ assimilation rate, however, the magnitude of this reduction depends on species and UV intensity. In agreement with our hypothesis, UV+ treatment reduced a negative effect of drought on $A_{\max }$ in $\mathrm{H}$. maculatum and A. capillaris, but not in R. obtusifolius. Noticeably, temporal stimulation of $A_{\max }$ by drought was observed in rhizomatous H. mollis at the beginning of drought stress period.

Drought stimulated an accumulation of epidermal flavonols in all species studied irrespective of UV treatment. At the end of the experiment, the highest flavonol contents were observed in plants grown under high UV and drought conditions demonstrating thus an additive interaction between these factors. Interactive effects of drought and UV radiation were most evident in R. obtusifolius and H. mollis.

Relationships between epidermal flavonol content and $\mathrm{CO}_{2}$ assimilation rate revealed a partial protective role of flavonols, particularly in A.capillaris and R.obtusifolius. Distinct relationships for control and drought-stressed plants documents, however, a minor effect of epidermal flavonols on protection of photosynthetic apparatus as compared to stomatal regulation. 


\section{Acknowledgement}

This work was supported by the Ministry of Education, Youth and Sports of CR within the National Sustainability Program I (NPU I), grant number LO1415.

\section{References}

Agrawal, S.B., Singh, S., Agrawal, M. 2009: Ultraviolet-B induced changes in gene expression and antioxidants in plants. Advances in Botanical Research, 52: 47-86.

Alexieva, V., Sergiev, I., Mapelli, S., Karanov, E. 2001: The effect of drought and ultraviolet radiation on growth and stress markers in pea and wheat. Plant Cell and Environment, 24: 1337-1344.

Balakumar, T., Vincent, V., Paliwal, K. 1993: On the interaction of UV-B radiation (280-315 $\mathrm{nm}$ ) with water stress in crop plants. Physiologia Plantarum, 87: 217-222.

Basu, S., Roychoudhury, A., Saha, P.P., SenGUPTA, D.N. 2010: Differential antioxidative responses of indica rice cultivars to drought stress. Plant Growth Regulation, 60: 51-59.

Cechin, I., Corniani, N., de Fátima Fumis, T., Cataneo, A.C. 2008: Ultraviolet-B and water stress effects on growth, gas exchange and oxidative stress in sunflower plants. Radiation and Environmental Biophysics, 47: 405-413.

Chaves, M. M., Maroco, J. P., Pereira, J. S. 2003: Understanding plant responses to droughtfrom genes to the whole plant. Functional Plant Biology, 30: 239-264.

Easterling, D.R., Meehl, G.A., Parmesan, C., Changnon, S.A., Karl, T.R., Mearns, L.O. 2000: Climate extremes: observations, modeling, and impacts. Science, 289: 2068-2074.

Gitz, D.C., Liu-Gitz, L. 2003: How do UV photomorphogenic responses confer water stress tolerance? Photochemistry and Photobiology, 78: 529-534.

Gitz, D.C., Liu-Gitz, L., BRitz, S. J., Sullivan, J.H. 2005: Ultraviolet-B effects on stomatal density, water-use efficiency, and stable carbon isotope discrimination in four glasshouse-grown soybean (Glyicine max) cultivars. Environmental and Experimental Botany, 53:343-355.

Hlavinka, P., Trnka, M., Semeradova, D., DubrovskÝ, M., ŽAlud, Z., MoŽNÝ, M. 2009. Effect of drought on yield variability of key crops in Czech Republic. Agricultural and Forest Meteorology, 149: 431-442.

Ibañez, S., Rosa, M., Hilal, M., González, J.A., Prado, F.E. 2008: Leaves of Citrus aurantifolia exhibit a different sensibility to solar UV-B radiation according to development stage in relation to photosynthetic pigments and UV-B absorbing compounds production. Journal of Photochemistry and Photobiology B: Biology, 90: 163-169.

JuriK, T.W., Снавот, J.F., Снавот, B.F. 1979: Ontogeny of photosynthetic performance in Fragaria virginiana under changing light regimes. Plant Physiology, 63: 542-547.

Klem, K., Holub, P., Štroch, M., Nezval, J., ŠPunda, V., TŘísKa, J., JANSEn, M.A.K., Robson, T.M., URBAN, O. 2015: Ultraviolet and photosynthetically active radiation can both induce photoprotective capacity allowing barley to overcome high radiation stress. Plant Physiology and Biochemistry, 93: 74-83.

Liancourt, P., Corcket, E., Michalet, R. 2005: Stress tolerance abilities and competitive responses in a watering and fertilization field experiment. Journal of Vegetation Science, 16: 713-722.

Ma, D., Sun, D., Wang, C., LI, Y., Guo, T. 2014: Expression of flavonoid biosynthesis genes and accumulation of flavonoid in wheat leaves in response to drought stress. Plant Physiology and Biochemistry, 80: 60-66.

Meijkamp, B., Aerts, R., Van de Staaij, J., TosserAms, M., ERnst, W.H.O., Rozema, J. 1999: Effects of UV-B on secondary metabolites in plants. In: Rozema, J. (ed.): Stratospheric ozone depletion: the effects of enhanced UV-B radiation on terrestrial ecosystems, Backhuys Publishers, Leiden, The Netherlands, 71-99.

Mittler, R. 2006: Abiotic stress, the field environment and stress combination. Trends in Plant Science, 11: 15-19.

Munné-Bosch, S., Alegre, L. 2004: Die and let live: leaf senescence contributes to plant survival under drought stress. Functional Plant Biology, 31: 203-216.

Nakabayashi, R., Yonekura-Sakakibara, K., Urano, K., Suzuki, M., Yamada, Y., NishizaWA, T., ET AL. 2014: Enhancement of oxidative and drought tolerance in Arabidopsis by over-accumulation of antioxidant flavonoids. The Plant Journal, 77: 367-379. 
Nogués, S., Allen, D.J., Morison, J.I., Baker, N.R. 1998: Ultraviolet-B radiation effects on water relations, leaf development, and photosynthesis in droughted pea plants. Plant Physiology, 117: 173-181.

Ono, K., Nishi, Y., Watanabe, A., Terashima, I. 2001: Possible mechanisms of adaptive leaf senescence. Plant Biology, 3: 234-243.

Ren, J., Dai, W., Xuan, Z., Yao, Y., Korpelainen, H., LI, C. 2007: The effect of drought and enhanced UV-B radiation on the growth and physiological traits of two contrasting poplar species. Forest Ecology and Management, 239: 112-119.

Schmidt, A.M., Ormrod, D.P., Livingston, N.J., MisRA, S. 2000: The interaction of ultraviolet-B radiation and water deficit in two Arabidopsis thaliana genotypes. Annals of Botany, 85: 571-575.

ShetTy, P., Atallah, M.T., Shetty, K. 2002: Effects of UV treatment on the proline-linked pentose phosphate pathway for phenolics and L-DOPA synthesis in dark germinated Viciafaba. Process Biochemistry, 37: 1285-1295.

TaO, F., Yokozawa, M., Hayashi, Y., Lin, E. 2003: Terrestrial water cycle and the impact of climate change. AMBIO: A Journal of the Human Environment, 32: 295-301.

Tattini, M., Galardi, C., Pinelli, P., Massai, R., Remorini, D., Agati, G. 2004: Differential accumulation of flavonoids and hydroxycinnamates in leaves of Ligustrum vulgare under excess light and drought stress. New Phytologist, 163: 547-561.

Winkel, T., Payne, W., Renno, J.F. 2001: Ontogeny modifies the effects of water stress on stomatal control, leaf area duration and biomass partitioning of Pennisetum glaucum. New Phytologist, 149: 71-82.

Xu, Z., ZHOU, G. 2011: Responses of photosynthetic capacity to soil moisture gradient in perennial rhizome grass and perennial bunchgrass. BMC Plant Biology, 11: 21-31. 